\title{
Use of Placental Growth Factor for Trisomy 21 Screening in Pregnancy: A Systematic Review
}

\author{
Ahmad Badeghiesh, MD, MPH ${ }^{1}$ Alexander Volodarsky-Perel, MD ${ }^{1,2}$ Ariane Lasry, BSc ${ }^{1}$ \\ Robert Hemmings, MD ${ }^{1,3}$ Yaron Gil, MD ${ }^{1}$ Jacques Balayla, MD, MPH, CIP, FRCSC \\ ${ }^{1}$ Department of Obstetrics and Gynecology, McGill University, \\ Montreal, Quebec, Canada \\ ${ }^{2}$ Lady Davis Research Institute, Jewish General Hospital, Montreal, \\ Quebec, Canada \\ Address for correspondence Jacques Balayla, MD, MPH, CIP, FRCSC, \\ Department of Obstetrics and Gynecology, Jewish General Hospital, McGill \\ University, 3755 Chemin de la Côte-Sainte-Catherine, Montréal, QC, Canada \\ H3T 1E2 (e-mail: jacques.balayla@mail.mcgill.ca).
}

${ }^{3}$ Department of Obstetrics and Gynecology, CIUSS Ouest de l'Ile, Montreal, Quebec, Canada

Am J Perinatol Rep 2020;10:e234-e240.

\begin{abstract}
Keywords

- PLGF

- placental growth factor

- trisomy 21

- prenatal screening

- aneuploidy

Background Prenatal serum screening is an important modality to screen for aneuploidy in pregnancy. The addition of placental growth factor (PLGF) to screen for trisomy 21 remains controversial.

Objective To determine whether the addition of PLGF to combined serum aneuploidy screening improves detection rates (DRs) for trisomy 21.

Study Design We performed a systematic review of the literature until October 2019 to determine the benefits of adding PLGF to prenatal screening. We performed a goodness-of-fit test and retrieved the coefficient of determinations $\left(R^{2}\right)$ as a function of false positive rates (FPRs), providing mean-weighted improvements in the DRs after accounting for PLGF levels.

Results We identified 51 studies, of which 8 met inclusion criteria (834 aneuploidy cases and 105,904 euploid controls). DRs were proportional to FPR across all studies, ranging from 59.0 to $95.3 \%$ without PLGF and 61.0 to $96.3 \%$ with PLGF (FPR 1-5\%). Goodness-of-fit regression analysis revealed a logarithmic distribution of DRs as a function of the FPR, with $R^{2}=0.109$ (no PLGF) and $R^{2}=0.06$ (PLGF). Two-sample Kolmogorov-Smirnov's test reveals a p-value of 0.44 . Overall, addition of PLGF improves DRs of $3.3 \%$ for $1 \%$ FPR, $1.7 \%$ for $3 \%$ FPR, and $1.4 \%$ for $5 \%$ FPR, respectively. Conclusion Addition of PLGF to prenatal screening using serum analytes mildly improves trisomy 21 DRs as a function of FPRs.
\end{abstract}

Placental growth factor (PLGF) is a human protein encoded by the PGF gene, which is a member of the vascular endothelial growth factor family, and is implicated in the angiogenesis and trophoblastic invasion of the maternal spiral arteries during placentation in early pregnancy. ${ }^{1}$ Maternal serum levels of PLGF at 11 to 13 weeks' gestation are decreased in pregnancies with impaired placentation resulting in increased risks for preeclampsia and delivery of small for gestational age (SGA) and growth restricted (intrauterine growth restriction) neonates. ${ }^{2}$

received

January 5, 2020 accepted after revision March 5, 2020
DOI https://doi.org/

10.1055/s-0040-1713785. ISSN 2157-6998.
Like other proteins used for either the combined firsttrimester screening (cFTS) or the integrated prenatal screening (IPS) of aneuploidies, such as serum-free human chorionic gonadotropin (hCG), pregnancy-associated plasma protein $\mathrm{A}$ (PAPP-A), unconjugated estriol ( $u E 3)$, and inhibin-A, PLGF is a protein of placental origin. ${ }^{3}$ Indeed, the main source of PLGF during pregnancy is the placental trophoblast, where it plays a key role in trophoblastic growth and differentiation. ${ }^{4}$

With the advent of noninvasive prenatal testing (NIPT) using maternal serum cell-free fetal DNA, the use of cFTS/IPS

Copyright $\odot 2020$ by Thieme Medical Publishers, Inc., 333 Seventh Avenue, New York, NY 10001, USA. Tel: +1(212) 760-0888.
License terms

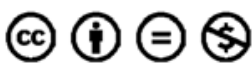


for detection of aneuploidy has decreased. However, serum screening remains the mainstay test for prenatal screening in the majority of patients in modern obstetrical practice in North America. ${ }^{5}$ Depending on maternal age (MA), this approach confers detection rates (DRs) for trisomy 21 between 86 and 95\%, and false-positive rates (FPRs) between 4 and $10 \%$, indicating that there exists room for clinical improvement. ${ }^{5}$ However, whether the addition of serum PLGF improves the DR of conventional serum screening with cFTS/IPS is controversial. ${ }^{6}$ It is conceivable that, where NIPT is unavailable or unaffordable, a more sensitive serum screening test may benefit a proportion of the population who lack access to cell-free DNA testing.

In this study, we conducted a systematic review to determine whether the measurement of serum PLGF improves the DRs of prenatal serum screen analytes while reducing the FPRs for aneuploidy screening.

\section{Materials and Methods}

\section{Literature Search and Study Selection}

We performed a Medline, Embase, Google Scholar, Scopus, Institute for Scientific Information Web of Science, and Cochrane database search, as well as PubMed (www. pubmed.gov) search until the end of October 2019 from the past 20 years using the following Boolean search criteria: placental growth factor OR PLGF, Trisomy OR aneuploidy, AND prenatal screening OR serum screening OR integrated screening OR combined screening. We restricted our research to studies in English, in humans, and made no distinction regarding country or journal of origin. The reference lists and bibliographies of included studies were then searched for other salient and pertinent articles. Finally, manual searches of studies belonging to research teams having prior PLGF and aneuploidy screening were reviewed, and other pertinent studies were retrieved. We used the Newcastle-Ottawa scale to assess the risk of bias in the studies included ( $\mathbf{- T a b l e ~} \mathbf{1}$ ).

\section{Data Extraction}

This review was modeled on the Preferred Reporting Items for Systematic Reviews and Meta-Analyses(PRISMA) statement. Our main inclusion criteria sought studies, which directly assessed the effects of adding PLGF to the IPS by providing DRs and their corresponding FPR values. Given its greater incidence, we focused primarily on the effects of adding PLGF for the detection of trisomy 21 (Down's syndrome), and collected information on the different detection modalities and metabolites used in each study. We excluded studies which simply assessed levels of PLGF throughout pregnancy, as well as those which described methodologies for its measurement in the laboratory. Likewise, individual case reports and expert opinion articles were excluded.

\section{Data Synthesis}

We used SPSS 24.0.0 (IBM, 2017) to perform a goodness-of-fit test and retrieve a coefficient of determination $\left(R^{2}\right)$ before and after the introduction of PGLF, as a function of FPRs. Finally, we performed a two-sample Kolmogorov-Smirnov's test to delineate differences in distributions of DR as function of FPR with and without PLGF and receiver-operating characteristic (ROC) curves are provided to illustrate sensitivities as a function of specificities in two studies. Forest plots were retrieved using Review Manager 5.3.5 (The Cochrane Collaboration, 2014). This study was exempted from Institutional Review Board approval because it is a systematic review and no identifiable patient data were used.

\section{Results}

We identified a total of 51 studies, of which 8 met inclusion criteria. A total of 3 prospective cohort studies and 5 casecontrol studies were included in our final analysis, for a total of 834 aneuploidy cases and 105,904 euploid control pregnancies. The search flowchart depicting the search strategy is illustrated in - Fig. 1. All studies used the following modalities to estimate aneuploidy risk: MA, nuchal translucency (NT), PAPP-A, and $\beta$-hCG. One study by Wright et al ${ }^{7}$ used $\alpha$ fetoprotein (AFP) levels and Doppler evaluation of the ductus venosus (DV) in addition to the aforementioned modalities.

DRs were proportional to FPRs across all studies, and ranged from 59.0 to $95.3 \%$ without the use of PLGF and 61.0 to $96.3 \%$ after accounting for PLGF. Goodness-of-fit regression analysis revealed a distribution of DRs as a function of the FPR, which exhibited a logarithmic distribution with $R^{2}=0.109$ in the no PLGF group and $R^{2}=0.06$ in the

Table 1 Newcastle-Ottawa scale to assess the quality of studies included

\begin{tabular}{|l|l|l|l|l|}
\hline Study & Study design & Selection & Comparability & Exposure or outcome \\
\hline Han et al $(2016)^{28}$ & Case-control & $\downarrow \downarrow$ & - & $\downarrow \downarrow$ \\
\hline Pandya et al $(2012)^{32}$ & Prospective cohort & $\downarrow \downarrow \downarrow \downarrow$ & - & $\downarrow \downarrow \downarrow$ \\
\hline Cowans et al $(2010)^{21}$ & Case-control & $\downarrow \downarrow$ & $\downarrow$ & $\downarrow \downarrow$ \\
\hline Kagan et al (2012) & Case-control & $\downarrow$ & $\downarrow \downarrow$ & $\downarrow \downarrow$ \\
\hline Zaragoza et al (2009) & Case-control & $\downarrow$ & - & $\downarrow \downarrow$ \\
\hline Wright et al $(2014)^{7}$ & Prospective cohort & $\downarrow \downarrow \downarrow \downarrow$ & $\downarrow$ \\
\hline Boutin et al $(2018)^{33}$ & Prospective cohort & $\downarrow \downarrow \downarrow \downarrow$ & $\downarrow \downarrow$ & $\downarrow \downarrow \downarrow$ \\
\hline Koster et al $(2011)^{29}$ & Case-control & $\downarrow \downarrow \downarrow$ & $\downarrow \downarrow$ & $\downarrow \downarrow$ \\
\hline
\end{tabular}




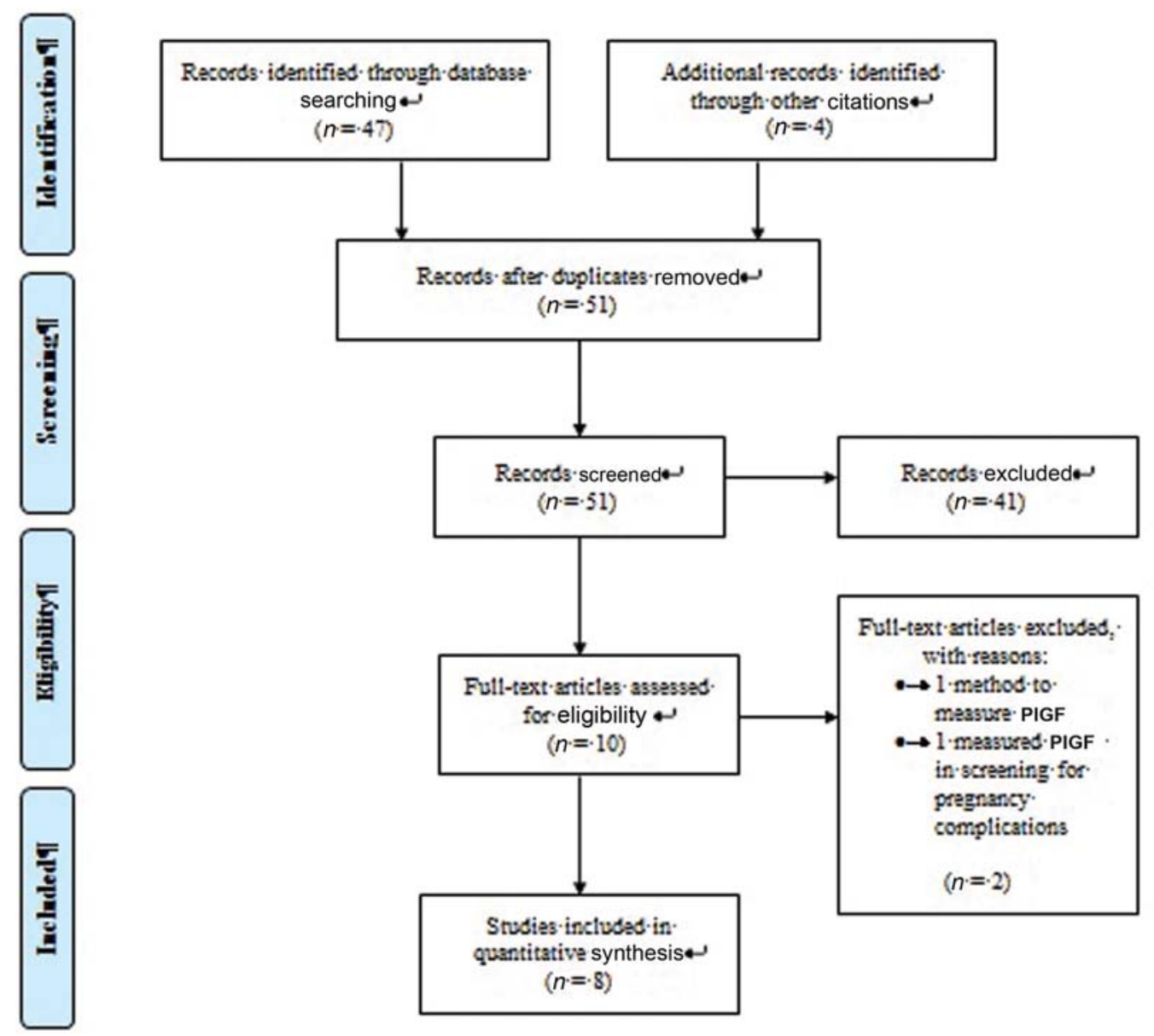

Fig. 1 Preferred Reporting Items for Systematic Reviews and Meta-Analyses (PRISMA) flowchart for the systematic review of studies. PLGF, placental growth factor.

PLGF group. These results indicate a poor fit of the model and large variation between DR for a given FPR across studies.

Two-sample Kolmogorov-Smirnov's test reveals a $p$-value of 0.44 indicating that curves with and without PLGF share a similar distribution. - Table 2 shows individual study data. -Fig. 2 reveals the improvements in DRs in serum screening samples containing PLGF. Upon addition of PLGF to the combined serum screening, average improvements in the DRs of $3.3 \%$ for a $1 \%$ FPR, $1.7 \%$ for a $3 \%$ FPR, and $1.4 \%$ for a $5 \%$ FPR were observed. Forest plot of DRs by study for a FPR of 3\% is provided in - Fig. 3. Finally, receiver-operating characteristic (ROC) curves pre/post-PLGF for studies by Han et al and Koster et al are shown in - Fig. 4.

\section{Discussion}

The first-trimester prenatal screening based on MA, NT, and biomarkers such as PAPP-A and $\beta$-hCG has shown great efficacy, and this screening modality remains one of the main approach used in modern obstetrical practice. ${ }^{8}$ In this study, we sought to determine whether the measurement of serum PLGF improves the DRs of prenatal serum screen analyses while reducing the FPRs for aneuploidy screening. Our findings suggest that the addition PLGF to prenatal screening test mildly improves trisomy 21 DRs between 1.4 and 3.3\%.
PLGF is produced during pregnancy primarily in placental trophoblasts. ${ }^{9}$ As mentioned previously, PLGF plays a significant role in trophoblast growth and differentiation. Trophoblast cells, especially extravillous trophoblast cells, are responsible for invading maternal arteries, ${ }^{10}$ where proper development of blood vessels in the placenta is critical for embryonic development. Under normal physiologic conditions, PLGF is secreted at lower levels in other organs as well, including the thyroid, heart, lung, and skeletal muscle, where PLGF levels are affected by gestational age and maternal characteristics, including age, body mass index, racial origin, and smoking status. ${ }^{11,12}$ In an uncomplicated pregnancy, PLGF concentrations are low in the first trimester and increase from weeks 11 to 12 and reach the peak at week 30 , after which it decreases once again. ${ }^{11}$

In preeclampsia, PLGF levels are significantly lower at the time of diagnosis as well as during the progression of the clinical syndrome. The decrease in PLGF concentration is likely due to both a combination of reduced primary expression of PLGF and reduced free PLGF due to binding with soluble fms-like tyrosine kinase- 1 , which is raised in affected women. ${ }^{13-15}$ Women are recognized at high risk for preeclampsia by using a combination of biomarkers, including PLGF, maternal characteristics, and uterine artery Doppler can benefit from using prophylactic aspirin in early 
Table 2 Studies included in the systematic review

\begin{tabular}{|c|c|c|c|c|c|c|c|c|}
\hline \multirow[t]{2}{*}{$\begin{array}{l}\text { Author } \\
\text { (year) }\end{array}$} & \multirow[t]{2}{*}{ Study design } & \multicolumn{2}{|c|}{$\begin{array}{l}\text { Number of pa- } \\
\text { tients }\end{array}$} & \multirow[t]{2}{*}{ Screening modalities } & \multirow{2}{*}{$\begin{array}{l}\text { Detection } \\
\text { rate of } \\
\text { screening } \\
\text { before adding } \\
\text { PLGF data }\end{array}$} & \multirow[t]{2}{*}{ FPR } & \multirow{2}{*}{$\begin{array}{l}\text { Detection } \\
\text { rate of } \\
\text { screening } \\
\text { after adding } \\
\text { PLGF data }\end{array}$} & \multirow[t]{2}{*}{ FPR } \\
\hline & & $\begin{array}{l}\text { Trisomy } \\
21\end{array}$ & Euploid & & & & & \\
\hline $\begin{array}{l}\text { Han et al } \\
(2016)^{28}\end{array}$ & Case-control & 42 & 558 & $\begin{array}{l}\mathrm{MA}+\mathrm{NT}+\mathrm{PAPP}-\mathrm{A}+ \\
\beta-\mathrm{hCG}+\mathrm{PLGF}\end{array}$ & $\begin{array}{l}88.4 \% \\
93.4 \% \\
95.3 \%\end{array}$ & $\begin{array}{l}1 \% \\
3 \% \\
5 \%\end{array}$ & $\begin{array}{l}89.9 \% \\
94.6 \% \\
96.3 \%\end{array}$ & $\begin{array}{l}1 \% \\
3 \% \\
5 \%\end{array}$ \\
\hline $\begin{array}{l}\text { Pandya et al } \\
(2012)^{32}\end{array}$ & $\begin{array}{l}\text { Prospective } \\
\text { cohort }\end{array}$ & 44 & 11,414 & $\begin{array}{l}\mathrm{MA}+\mathrm{NT}+\mathrm{PAPP}-\mathrm{A}+ \\
\beta-\mathrm{hCG}+\mathrm{PLGF}\end{array}$ & $85.0 \%$ & $2.7 \%$ & $88.0 \%^{\mathrm{a}}$ & $2.6 \%$ \\
\hline $\begin{array}{l}\text { Cowans et al } \\
(2010)^{21}\end{array}$ & Case-control & 70 & 375 & $\begin{array}{l}\text { MA+ NT + PAPP-A + } \\
\beta-h C G+\text { PLGF }\end{array}$ & $\begin{array}{l}92.9 \% \\
94.5 \%\end{array}$ & $\begin{array}{l}3 \% \\
5 \%\end{array}$ & $\begin{array}{l}93.3 \% \\
94.9 \%\end{array}$ & $\begin{array}{l}3 \% \\
5 \%\end{array}$ \\
\hline $\begin{array}{l}\text { Kagan et al } \\
(2012)^{18}\end{array}$ & Case-control & 100 & 409 & $\begin{array}{l}\mathrm{MA}+\mathrm{NT}+\mathrm{PAPP}-\mathrm{A}+ \\
\beta-\mathrm{hCG}+\mathrm{PLGF}\end{array}$ & $85.0 \%$ & $2.7 \%$ & $87.0 \%$ & $2.6 \%$ \\
\hline $\begin{array}{l}\text { Zaragoza } \\
\text { et al }(2009)^{22}\end{array}$ & Case-control & 90 & 609 & $\begin{array}{l}\mathrm{MA}+\mathrm{NT}+\mathrm{PAPP}-\mathrm{A}+ \\
\beta-\mathrm{hCG}+\mathrm{PLGF}\end{array}$ & $\begin{array}{l}71.1 \% \\
76.7 \%\end{array}$ & $\begin{array}{l}3 \% \\
5 \%\end{array}$ & $\begin{array}{l}70.0 \% \\
80.0 \%\end{array}$ & $\begin{array}{l}3 \% \\
5 \%\end{array}$ \\
\hline $\begin{array}{l}\text { Wright et al } \\
(2014)^{7}\end{array}$ & $\begin{array}{l}\text { Prospective } \\
\text { cohort }\end{array}$ & 324 & 86,917 & $\begin{array}{l}\mathrm{MA}+\mathrm{NT}+\mathrm{PAPP}-\mathrm{A}+ \\
\beta-\mathrm{hCG}+\mathrm{PLGF} \\
+\mathrm{AFP}+\mathrm{DV}\end{array}$ & $87.0 \%$ & $2.2 \%$ & $93.3 \%$ & $1.3 \%$ \\
\hline $\begin{array}{l}\text { Boutin et al } \\
(2018)^{33}\end{array}$ & $\begin{array}{l}\text { Prospective } \\
\text { cohort }\end{array}$ & 13 & 4,765 & $\mathrm{MA}+\mathrm{NT}+\mathrm{PLGF}$ & - & - & $92.0 \%$ & $5 \%$ \\
\hline $\begin{array}{l}\text { Koster et al } \\
(2011)^{29}\end{array}$ & Case-control & 151 & 847 & $\begin{array}{l}\mathrm{MA}+\mathrm{NT}+\mathrm{PAPP}-\mathrm{A}+ \\
\beta-\mathrm{hCG}+\mathrm{PLGF}\end{array}$ & $\begin{array}{l}59.0 \% \\
71.0 \% \\
77.0 \%\end{array}$ & $\begin{array}{l}1 \% \\
3 \% \\
5 \%\end{array}$ & $\begin{array}{l}61.0 \% \\
73.0 \% \\
78.0 \%\end{array}$ & $\begin{array}{l}1 \% \\
3 \% \\
5 \%\end{array}$ \\
\hline
\end{tabular}

Abbreviations: AFP, $\alpha$-fetoprotein; $\beta$-hCG, $\beta$ human chorionic gonadotropin; DV, ductus venosus; FPR, false-positive rate; MA, maternal age; NT, nuchal translucency; PAPP-A, pregnancy-associated plasma protein; PLGF, placental growth factor.

${ }^{a}$ Risk cutoff of $1 / 100$.

pregnancy. ${ }^{16,17}$ Although in screening for preeclampsia, PLGF gives higher DRs than PAPP-A and free $\beta$-hCG, the study by Kagan et $\mathrm{al}^{18}$ has shown that the replacement of PAPP-A or free $\beta$-hCG by PLGF results in a significant reduction in the DR of trisomy 21 as a consequence. A low level of PLGF is apparently both a consequence of early abnormal placentation and a causative factor to continued abnormal growth during the latter half of pregnancy. Therefore, in women without preeclampsia, who give birth to SGA infants also have, on average, lower levels of PLGF. ${ }^{15}$

In trisomy 21, several studies have examined PLGF, but disagreement exists on how levels differ in cases relative to controls. In the first trimester, some of the studies reported that PLGF levels in trisomy 21 increased, ${ }^{19,20}$ and others reported decreased ${ }^{21,22}$ relative to expected baseline. Likewise, in the second trimester, PLGF has also been found to be increased, ${ }^{23}$ decreased, ${ }^{24}$ and unchanged ${ }^{25,26}$ in cases of trisomy 21. However, these inconsistencies in the literature may be due to which immunoassay methods were used to measure PLGF as mentioned in the article by Cowans et al. ${ }^{27}$

In our study, we focused primarily on the effects of adding PLGF for the detection of trisomy 21 and we found a large variation between DR for a given FPR across studies as a poor fit of the model. Also, our analysis reveals average improves trisomy 21 DRs between 1.4 and 3.3\% for FPRs between 5 and $1 \%$, respectively. Among the studies that were included in our research, we found only two studies that reported FPR as 1,2, and $5 \%$, which are Han et $\mathrm{al}^{28}$ and Koster et $\mathrm{al}^{29}$ We performed ROC curves for these studies.
While PLGF may be a beneficial addition to the classical combined screening for preeclampsia and trisomy 21, it would increase the direct cost of such screening. However, one must consider the potential long-term savings associated with increased detection of trisomy 21 and subsequent termination of affected pregnancies. For example, care of an individual with trisomy 21 entails numerous medical visits and lifelong access to health care services, as well as to several social and housing services. The assessment of cost-benefit is also confounded by cost attributed to the care of a trisomy 21 affected child. Care for a child affected with trisomy 21 is assumed to bring about a cost of approximately U.S. $\$ 700,000$ for the first 4 years of medical care in the United States, ${ }^{30}$ with up to U.S. $\$ 125,000^{31}$ depending on whether the child at birth did or did not have a heart defect. Which figure is used is going to have a significant impact of any cost-benefit analysis.

Moreover, one possible advantage of adding PLGF to serum screening exists in screening programs which only offer NIPT screening for a given risk level in the cFTS/IPS. As an example, in one of our clinics, we only offer NIPT contingent on the serum screen if the cFTS/IPS risk is more than $1: 2,500$. The implementation of that cutoff led to a reduction in the number of NIPT offered to around 3\%, largely reducing cost and personnel use. This could represent a significant saving when applied to a provincial/state/national screening program. Thus, despite the mildly increased DR of trisomy 21 by adding PLGF to first-trimester screening, there may in fact be long-term cost savings of routinely adding this marker 


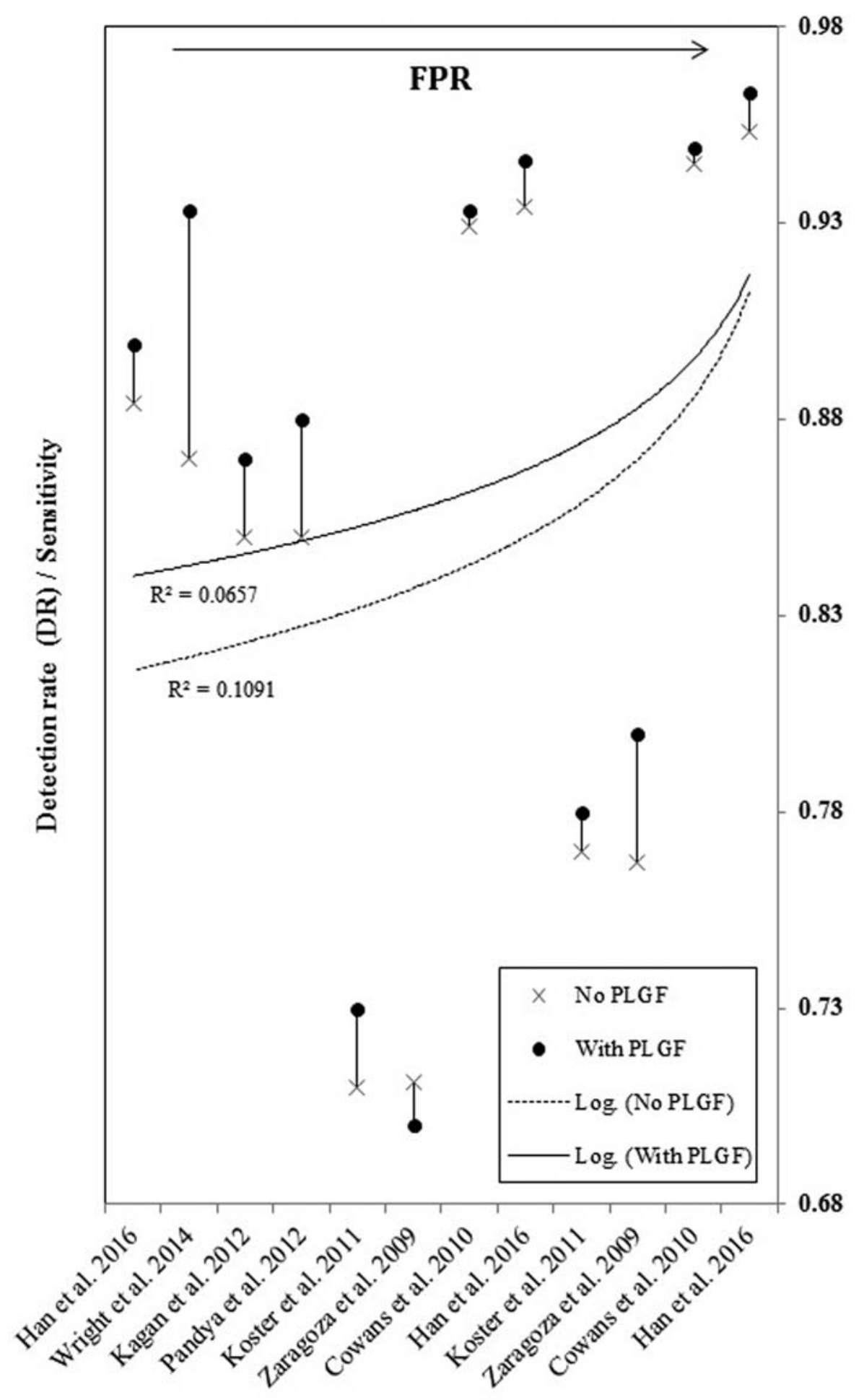

Fig. 2 Aneuploidy detection rates before and after PLGF from 1\% to 5\% FPR. FPR, false-positive rate; PLGF, placental growth factor.

both to patients and the health care system. Future studies should be aimed at addressing the cost-benefit analysis of implementing PLGF into routine prenatal screening. Furthermore, it is imperative that any time the efficacy of a treatment/technology/process is evaluated, that it be compared with a gold standard. Nowadays, the screening gold standard remains NIPT with cell-free DNA, with sensitivity and specificity for trisomy 21 approaching $100 \%$. As we have reported in this study, unfortunately, the addition of PLGF to serum screening analytes does not approach these values. The difference in efficacy might be nevertheless justified in the lesser cost of serum analytes screening and the lack of widespread availability of NIPT as described earlier.

\section{Strengths and Limitations}

The strengths of this study are multiple and include the large number of patients analyzed, the consistency of findings 


\begin{tabular}{|c|c|c|c|c|c|c|c|c|}
\hline \multicolumn{9}{|c|}{ Trisomy 21 detection rate before adding PIGF data } \\
\hline Study & TP & FP & FN & $\mathrm{TN}$ & Sensitivity $(95 \% \mathrm{Cl})$ & Specificity $(95 \% \mathrm{Cl})$ & Sensitivity $(95 \% \mathrm{CI})$ & Specificity $(95 \% \mathrm{CI})$ \\
\hline Cowans 2010 & 65 & 13 & 5 & 432 & $0.93[0.84,0.98]$ & $0.97[0.95,0.98]$ & $\rightarrow$ & 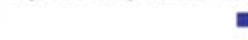 \\
\hline Han 2016 & 39 & 18 & 3 & 582 & $0.93[0.81,0.99]$ & $0.97[0.95,0.98]$ & $\rightarrow$ & - \\
\hline Kagan 2012 & 85 & 14 & 15 & 505 & $0.85[0.76,0.91]$ & $0.97[0.96,0.99]$ & $\rightarrow$ & $=$ \\
\hline Koster 2011 & 107 & 30 & 44 & 968 & $0.71[0.63,0.78]$ & $0.97[0.96,0.98]$ & $\rightarrow$ & = \\
\hline Pandaya 2012 & 37 & 309 & 7 & 11149 & $0.84[0.70,0.93]$ & $0.97[0.97,0.98]$ & & $=$ \\
\hline Wright 2014 & 282 & 1919 & 42 & 85322 & $0.87[0.83,0.90]$ & $0.98[0.98,0.98]$ & 틀 & - \\
\hline Zaragoza 2009 & 64 & 21 & 26 & 678 & $0.71[0.61,0.80]$ & $0.97[0.95,0.98]$ & & = \\
\hline \multicolumn{9}{|c|}{ Trisomy 21 detection rate after adding PIGF data } \\
\hline Study & TP & FP & FN & $\mathrm{TN}$ & Sensitivity $(95 \% \mathrm{CI})$ & Specificity $(95 \% \mathrm{Cl})$ & Sensitivity $(95 \% \mathrm{CI})$ & Specificity $(95 \% \mathrm{Cl})$ \\
\hline Cowans 2010 & 65 & 13 & 5 & 432 & $0.93[0.84,0.98]$ & $0.97[0.95,0.98]$ & $\rightarrow$ & 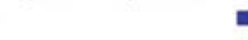 \\
\hline Han 2016 & 40 & 18 & 2 & 582 & $0.95[0.84,0.99]$ & $0.97[0.95,0.98]$ & $\rightarrow$ & $=$ \\
\hline Kagan 2012 & 87 & 13 & 13 & 506 & $0.87[0.79,0.93]$ & $0.97[0.96,0.99]$ & $\rightarrow$ & - \\
\hline Koster 2011 & 110 & 30 & 41 & 968 & $0.73[0.65,0.80]$ & $0.97[0.96,0.98]$ & $\rightarrow$ & $=$ \\
\hline Pandaya 2012 & 39 & 298 & 5 & 11160 & $0.89[0.75,0.96]$ & $0.97[0.97,0.98]$ & $\rightarrow$ & $=$ \\
\hline Wright 2014 & 302 & 1134 & 22 & 86107 & $0.93[0.90,0.96]$ & $0.99[0.99,0.99]$ & = & 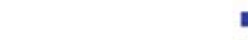 \\
\hline Zaragoza 2009 & 63 & 21 & 27 & 678 & $0.70[0.59,0.79]$ & $0.97[0.95,0.98]$ & 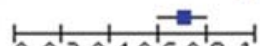 & \\
\hline
\end{tabular}

Fig. 3 Forest plot of detection rates by study for a FPR of 3\%. FPR, false-positive rate; PLGF, placental growth factor.
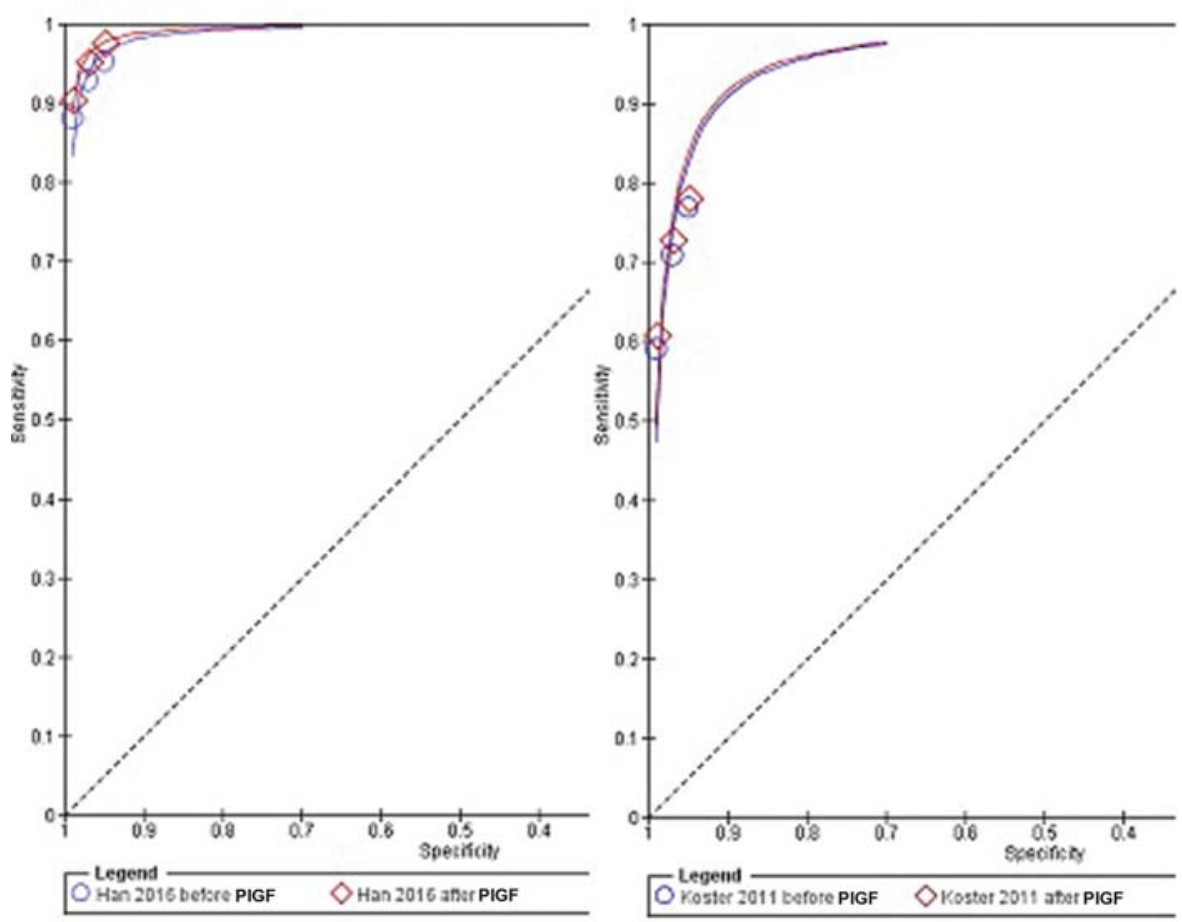

Fig. 4 Receiver-operating characteristic curves pre/post-PLGF for studies by Han et al and Koster et al. FPR, false-positive rate; PLGF, placental growth factor.

across studies, and the statistical methodology used. Likewise, to the best of our knowledge, this it is the first systemic review discussing the use of PLGF for aneuploidy screening in pregnancy. On the contrary, several limitations are worth noting. First, though the improvements in DRs following the introduction of PLGF were consistent across studies, the actual DRs between reports were significantly different, indicating significant heterogeneity between studies. Second, differences between the analytes studied in two out of the eight studies, which included the use of AFP and DV may have introduced significant bias. Finally, given the nature of the literature available, we combined different study designs to arrive at our conclusions, which may have impacted our results.

\section{Conclusion}

In conclusion, addition of PLGF to prenatal screening using serum analytes mildly improves trisomy 21 DRs between 1.4 and 3.3\% for FPRs between 5 and 1\%, respectively. As the use of NIPT becomes increasingly widespread, future studies should address the cost-benefit analysis of introducing PLGF for prenatal screening with serum analytes. 
Funding

None.

Conflict of Interest
None declared.

\section{References}

1 Coultas L, Chawengsaksophak K, Rossant J. Endothelial cells and VEGF in vascular development. Nature 2005;438(7070):937-945

2 Schlembach D, Wallner W, Sengenberger R, et al. Angiogenic growth factor levels in maternal and fetal blood: correlation with Doppler ultrasound parameters in pregnancies complicated by pre-eclampsia and intrauterine growth restriction. Ultrasound Obstet Gynecol 2007;29(04):407-413

3 Kagan KO, Wright D, Spencer K, Molina FS, Nicolaides KH. Firsttrimester screening for trisomy 21 by free beta-human chorionic gonadotropin and pregnancy-associated plasma protein-A: impact of maternal and pregnancy characteristics. Ultrasound Obstet Gynecol 2008;31(05):493-502

4 Pollheimer J, Knöfler M. Signalling pathways regulating the invasive differentiation of human trophoblasts: a review. Placenta 2005;26(Suppl A):S21-S30

5 Chitayat D, Langlois S, Douglas Wilson R,; SOGC GENETICS COMMITTEE; CCMG PRENATAL DIAGNOSIS COMMITTEE. Prenatal screening for fetal aneuploidy in singleton pregnancies. J Obstet Gynaecol Can 2011;33(07):736-750

6 Huang T, Dennis A, Meschino WS, Rashid S, Mak-Tam E, Cuckle H. First trimester screening for Down syndrome using nuchal translucency, maternal serum pregnancy-associated plasma protein A, free- $\beta$ human chorionic gonadotrophin, placental growth factor, and $\alpha$-fetoprotein. Prenat Diagn 2015;35(07):709-716

7 Wright D, Syngelaki A, Bradbury I, Akolekar R, Nicolaides KH. Firsttrimester screening for trisomies 21,18 and 13 by ultrasound and biochemical testing. Fetal Diagn Ther 2014;35(02):118-126

8 Wheeler DM, Sinosich MJ. Prenatal screening in the first trimester of pregnancy. Prenat Diagn 1998;18(06):537-543

9 Khalil A, Muttukrishna S, Harrington K, Jauniaux E. Effect of antihypertensive therapy with alpha methyldopa on levels of angiogenic factors in pregnancies with hypertensive disorders. PLoS One 2008;3(07):e2766

10 Shore VH, Wang TH, Wang CL, Torry RJ, Caudle MR, Torry DS. Vascular endothelial growth factor, placenta growth factor and their receptors in isolated human trophoblast. Placenta 1997;18(08):657-665

11 Saffer C, Olson G, Boggess KA, Beyerlein R, Eubank C, Sibai BM; NORMALS Study Group. Determination of placental growth factor (PIGF) levels in healthy pregnant women without signs or symptoms of preeclampsia. Pregnancy Hypertens 2013;3(02):124-132

12 Lai J, Garcia-Tizon Larroca S, Peeva G, Poon LC, Wright D, Nicolaides $\mathrm{KH}$. Competing risks model in screening for preeclampsia by serum placental growth factor and soluble fms-like tyrosine kinase- 1 at 30-33 weeks' gestation. Fetal Diagn Ther 2014;35(04):240-248

13 Levine RJ, Maynard SE, Qian C, et al. Circulating angiogenic factors and the risk of preeclampsia. N Engl J Med 2004;350(07):672-683

14 Chau K, Hennessy A, Makris A. Placental growth factor and preeclampsia. J Hum Hypertens 2017;31(12):782-786

15 Poon LC, Zaragoza E, Akolekar R, Anagnostopoulos E, Nicolaides $\mathrm{KH}$. Maternal serum placental growth factor (PIGF) in small for gestational age pregnancy at $11(+0)$ to $13(+6)$ weeks of gestation. Prenat Diagn 2008;28(12):1110-1115

16 Bujold E, Roberge S, Lacasse Y, et al. Prevention of preeclampsia and intrauterine growth restriction with aspirin started in early pregnancy: a meta-analysis. Obstet Gynecol 2010;116(2 Pt 1): $402-414$
17 Rolnik DL, Wright D, Poon LC, et al. Aspirin versus placebo in pregnancies at high risk for preterm preeclampsia. N Engl J Med 2017;377(07):613-622

18 Kagan KO, Hoopmann M, Abele H, Alkier R, Lüthgens K. Firsttrimester combined screening for trisomy 21 with different combinations of placental growth factor, free $\beta$-human chorionic gonadotropin and pregnancy-associated plasma protein-A. Ultrasound Obstet Gynecol 2012;40(05):530-535

19 Cowans NJ, Stamatopoulou A, Tørring N, Spencer K. Early firsttrimester maternal serum placental growth factor in trisomy 21 pregnancies. Ultrasound Obstet Gynecol 2011;37(05):515-519

20 Spencer K, Liao AW, Ong CY, Geerts L, Nicolaides KH. First trimester maternal serum placenta growth factor (PIGF)concentrations in pregnancies with fetal trisomy 21 or trisomy 18 . Prenat Diagn 2001;21(09):718-722

21 Cowans NJ, Stamatopoulou A, Spencer K. First trimester maternal serum placental growth factor in trisomy 21 pregnancies. Prenat Diagn 2010;30(05):449-453

22 Zaragoza E, Akolekar R, Poon LC, Pepes S, Nicolaides KH. Maternal serum placental growth factor at 11-13 weeks in chromosomally abnormal pregnancies. Ultrasound Obstet Gynecol 2009;33(04): 382-386

23 Su YN, Hsu JJ, Lee CN, Cheng WF, Kung CC, Hsieh FJ. Raised maternal serum placenta growth factor concentration during the second trimester is associated with Down syndrome. Prenat Diagn 2002;22(01):8-12

24 Debieve F, Moiset A, Thomas K, Pampfer S, Hubinont C. Vascular endothelial growth factor and placenta growth factor concentrations in Down's syndrome and control pregnancies. Mol Hum Reprod 2001;7(08):765-770

25 Cowans NJ, Kisanga MC, Spencer K. Maternal serum placental growth factor in second trimester trisomy 21 pregnancies. Prenat Diagn 2012;32(02):117-121

26 Lambert-Messerlian GM, Canick JA. Placenta growth factor levels in second-trimester maternal serum in Down syndrome pregnancy and in the prediction of preeclampsia. Prenat Diagn 2004; 24(11):876-880

27 Cowans NJ, Kisanga M, Khan A, Spencer K. A comparison of two immunoassay methods for the measurement of maternal serum placental growth factor in early pregnancy. Fetal Diagn Ther 2012; 31(04):254-259

28 Han J, Liu H, Xu ZP, et al. Maternal serum PIGF (placental growth factor) in Chinese women in the first trimester undergoing screening for Down syndrome. Eur J Obstet Gynecol Reprod Biol 2016;201:166-170

29 Koster MP, Wortelboer EJ, Stoutenbeek P, Visser GH, Schielen PC. Modeling Down syndrome screening performance using firsttrimester serum markers. Ultrasound Obstet Gynecol 2011;38 (02):134-139

30 Benn P, Borell A, Chiu R, et al. Position statement from the Aneuploidy Screening Committee on behalf of the Board of the International Society for Prenatal Diagnosis. Prenat Diagn 2013; 33(07):622-629

31 Boulet SL, Molinari NA, Grosse SD, Honein MA, Correa-Villaseñor A. Health care expenditures for infants and young children with Down syndrome in a privately insured population. J Pediatr 2008; 153(02):241-246

32 Pandya P, Wright D, Syngelaki A, Akolekar R, Nicolaides KH. Maternal serum placental growth factor in prospective screening for aneuploidies at 8-13 weeks' gestation. Fetal Diagn Ther 2012; 31(02):87-93

33 Boutin A, Demers S, Gasse C, et al. First trimester screening for fetal aneuploidies using placental growth factor: the Great Obstetrical Syndrome (GOS) study. J Obstet Gynaecol Can 2018;40 (08):1044-1049 